\title{
Rapid selective separation of americium/curium from simulated nuclear forensic matrices using triazine ligands
}

Article

Published Version

Higginson, M. A., Thompson, P., Marsden, O. J., Livens, F. R., Harwood, L. M., Lewis, F. W., Hudson, M. J. and Heath, S. L. (2015) Rapid selective separation of americium/curium from simulated nuclear forensic matrices using triazine ligands. Radiochimica Acta, 103 (10). ISSN 0033-8230 doi: https://doi.org/10.1515/ract-2015-2403 Available at https://centaur.reading.ac.uk/58196/

It is advisable to refer to the publisher's version if you intend to cite from the work. See Guidance on citing.

To link to this article DOI: http://dx.doi.org/10.1515/ract-2015-2403

Publisher: Oldenbourg Gruppe

All outputs in CentAUR are protected by Intellectual Property Rights law, including copyright law. Copyright and IPR is retained by the creators or other copyright holders. Terms and conditions for use of this material are defined in the End User Agreement. 


\section{CentAUR}

Central Archive at the University of Reading

Reading's research outputs online 
Matthew A. Higginson, Paul Thompson, Olivia J. Marsden, Francis R. Livens, Laurence M. Harwood, Frank W. Lewis, Michael J. Hudson, and Sarah L. Heath*

\section{Rapid selective separation of americium/curium from simulated nuclear forensic matrices using triazine ligands}

DOI 10.1515/ract-2015-2403

Received February 24, 2015; accepted June 3, 2015; published online July 6, 2015

\begin{abstract}
In analysis of complex nuclear forensic samples containing lanthanides, actinides and matrix elements, rapid selective extraction of $\mathrm{Am} / \mathrm{Cm}$ for quantification is challenging, in particular due the difficult separation of $\mathrm{Am} / \mathrm{Cm}$ from lanthanides. Here we present a separation process for $\mathrm{Am} / \mathrm{Cm}$ (III) which is achieved using a combination of AG1-X8 chromatography followed by $\mathrm{Am} / \mathrm{Cm}$ extraction with a triazine ligand. The ligands tested in our process were $\mathrm{CyMe}_{4}$-BTPhen, $\mathrm{CyMe}_{4}$ BTBP, CA-BTP and CA-BTPhen. Our process allows for purification and quantification of $\mathrm{Am}$ and $\mathrm{Cm}$ (recoveries $80 \%-100 \%$ ) and other major actinides in $<2 \mathrm{~d}$ without the use of multiple columns or thiocyanate. The process is unaffected by high level $\mathrm{Ca}(\mathrm{II}) / \mathrm{Fe}(\mathrm{III}) / \mathrm{Al}(\mathrm{III})$ $\left(10 \mathrm{mg} \mathrm{mL} \mathrm{m}^{-1}\right)$ and thus requires little pre-treatment of samples.
\end{abstract}

Keywords: Americium separation, nuclear forensics, triazine ligand, BTPhen, BTBP.

\section{Introduction}

Nuclear forensic techniques aim to characterise unknown radioactive materials to provide evidence for use in le-

*Corresponding author: Sarah L. Heath, Centre for Radiochemistry Research, School of Chemistry, The University of Manchester, Manchester, M13 9PL, UK, e-mail: sarah.l.heath@manchester.ac.uk Matthew A. Higginson, Francis R. Livens: Centre for Radiochemistry Research, School of Chemistry, The University of Manchester, Manchester, M13 9PL, UK

Paul Thompson, Olivia J. Marsden: AWE, Aldermaston, Reading, RG7 4PR, UK

Laurence M. Harwood, Michael J. Hudson: Department of Chemistry, University of Reading, Whiteknights, Reading, RG6 6AD, UK Frank W. Lewis: Department of Chemistry, University of Reading, Whiteknights, Reading, RG6 6AD, UK; and Department of Chemical and Forensic Sciences, Faculty of Health and Life Sciences, Northumbria University, Newcastle upon Tyne NE1 8ST, UK gal cases, for example in seizures of illicit nuclear material. The collection of data must be performed in a timely manner and analytical techniques must be strategically applied to minimise sample loss/damage (i.e. non-destructive techniques applied first). Although the methodology of investigation will be driven by the specific sample, details of elemental and isotopic composition are required to allow comparison with reference data. This requires multiple analytical methods (e.g. radiometric methods, mass spectrometry) to be applied to the sample. However, samples in nuclear forensics can be complex, containing lanthanides, actinides and matrix elements, including fission/activation products with isotopic variation. Radiochemical separation is therefore required in order to avoid isobaric and polyatomic interferences (e.g. ${ }^{232} \mathrm{U} /{ }^{232} \mathrm{Th}$ ) in mass spectrometry and/or spectral overlap in radiometric analyses [1-3].

The inability to obtain pure fractions of the lanthanides and $\mathrm{Am} / \mathrm{Cm}$ is currently a bottleneck in nuclear forensic investigations of such samples. Pure solutions are necessary to avoid the interferences stated above and avoid problems in the electro-deposition and obtain a high quality data set for modelling. While some methods have been reported which achieve this in 1-2 $\mathrm{d}$ [4-6], these processes require multiple column steps and/or rely on the use of thiocyanate for Am elution, resulting in toxic wastes. More commonly, separation of $\mathrm{Am} / \mathrm{Cm}$ and lanthanides from these complex samples requires a process which may take up to $7 \mathrm{~d}$ (Figure 1).

We envisaged a simplified process in which $\mathrm{Am} / \mathrm{Cm}$, actinides and lanthanides could be extracted and quantified from a complex nuclear forensic sample in $<2 \mathrm{~d}$, whilst also avoiding the production of toxic waste. Specifically, this would entail separation of the major actinides (U(VI), Pu(IV), Np(IV)) by chromatography using current methods, followed by extraction of $\mathrm{Am} / \mathrm{Cm}$ (III) from the remaining matrix containing lanthanides and matrix elements.

Multiple soft-N donor ligands based on 1,2,4triazines have shown selectivity for complexation with $\mathrm{Am} / \mathrm{Cm}$ (III) over other actinides and lanthanides, with 


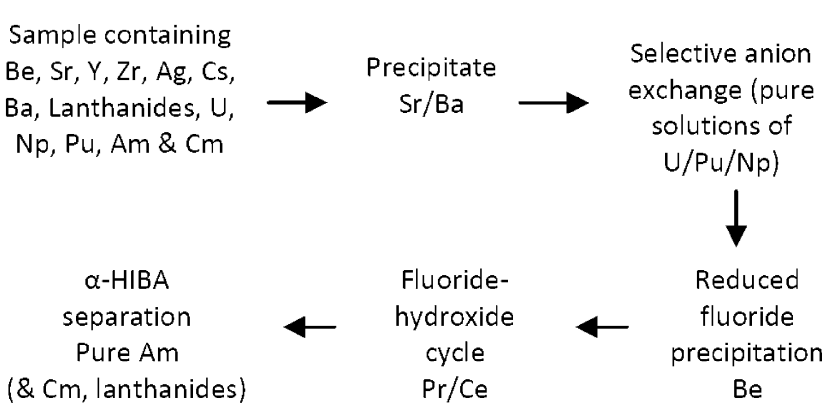

Fig. 1: Example of Am separation for a nuclear debris sample.

separation factors $>100$ [7]. This can be attributed to the enhanced covalency in bonds formed by the $5 f$ orbitals of the actinides, which confers apreference for softer ligands [8]. In our process, we desired a decontamination factor of $>1000$ for $\mathrm{Am} / \mathrm{Cm}$ (III), which could theoretically be achieved by ligands with such separation factors. Therefore, we identified four ligands based on the triazine motif for potential application in the extraction of $\mathrm{Am} / \mathrm{Cm}$ (III) from a complex nuclear forensics matrix (Figure 2). Herein we report application of these ligands to the extraction of $\mathrm{Am} / \mathrm{Cm}$ (III) from aqueous matrices containing lanthanides and matrix elements which are representative of complex nuclear forensic samples for the development of a rapid $\mathrm{Am} / \mathrm{Cm}(\mathrm{III})$ separation process. The matrices applied contain lanthanides, actinides and matrix elements, including fission/activation products which simulate a complex sample. Subsequently we have also shown that a related ligand immobilised on the solid support (PVB-Me $\mathrm{B}_{4} \mathrm{BTPhen}$ ) is capable of Am separation from complex matrices [11].
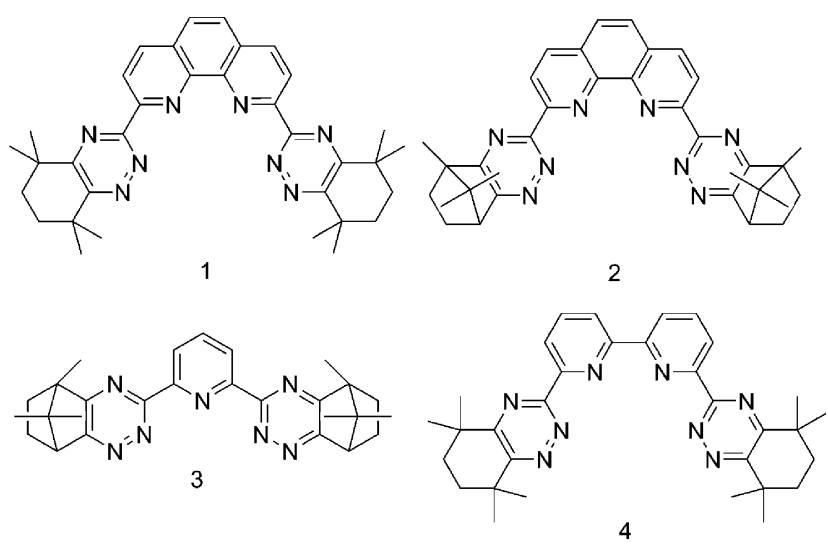

Fig. 2: Structures of the ligands used in this comparison study.

\section{Experimental}

All radionuclides used were provided from calibrated stocks in the School of Chemistry, University of Manchester. Micropipettes of $100 \mu \mathrm{L}, 0.1-1 \mathrm{~mL}$ and $2-10 \mu \mathrm{L}$ were calibrated on a 4 d.p. balance with $>18 \mathrm{M} \Omega$ deionised water in the temperature range $18-22^{\circ} \mathrm{C}$ and were found to be within their stated range. All acid solutions were made from analytical grade concentrated solutions and were diluted with $>18 \mathrm{M} \Omega$ deionised water. All solutions were considered to have expired within one month of creation. Gamma counting was performed using a Canberra 2020 coaxial HPGe gamma spectrometer with an Ortec 919E multi-channel analyser. Gamma spectroscopy was performed against a standard of known activity counted in the same geometry and analysed using the diagnostic photon energies of ${ }^{241} \mathrm{Am}(59.5 \mathrm{keV})$ and ${ }^{152} \mathrm{Eu}(121.8 \mathrm{keV})$. Samples were electroplated and alpha spectrometry was performed on a Canberra model 7401VR detector with multi-channel analyser. ICP-MS analysis was performed on an Agilent $7500 \mathrm{cx}$ spectrometer. Multiple standards for each element in the range 1-100 ppb were used for ICP-MS quantification. All reagents and solvents used were of standard analytical grade unless otherwise stated.

\subsection{Ligand synthesis}

$\mathrm{CyMe}_{4} \mathrm{BTPhen} \mathrm{CyMe}_{4} \mathrm{BTBP}$ and CA-BTP were synthesised as reported previously [12-14], and purified using the method reported by Whittaker et al [14]. CA-BTPhen was synthesised using a modification of the previously reported procedure [15], in which the solvent was changed to EtOH and the reaction time changed to $3 \mathrm{~h}$ reflux followed by $6 \mathrm{~h}$ at RT. CA-BTP was purified in the same manner as the other three ligands. Data collected for all intermediates and ligands was as previously reported.

\section{2 $\mathrm{Am} / \mathrm{Cm}$ separation from normal nuclear forensics matrix}

Generation of matrix: Using $4 \mathrm{M} \mathrm{HCl}$ (VWR, AnalaR NORMAPUR ${ }^{\circledR}$ grade) a solution containing $\sim 1 \mathrm{mg} \mathrm{mL}^{-1}$ of metal was prepared by dissolving the following elements in the chloride form (Sigma-Aldrich or Fluka, $>99.99 \%$ trace metal): $\mathrm{Be}(\mathrm{II}), \mathrm{Cs}(\mathrm{I}), \mathrm{Mo}(\mathrm{VI}), \mathrm{Ce}(\mathrm{III})$, $\operatorname{Pr}(\mathrm{III}), \mathrm{Nd}(\mathrm{III}), \mathrm{Sm}(\mathrm{III}), \mathrm{Tb}(\mathrm{III}), \mathrm{Y}(\mathrm{III}), \mathrm{Zr}(\mathrm{IV})$, $\mathrm{Ag}(\mathrm{I}), \mathrm{Cd}(\mathrm{II}), \mathrm{Sr}(\mathrm{II})$ and $\mathrm{Ba}(\mathrm{II})$. Spike solutions of ${ }^{241} \mathrm{Am}$ (III, $\quad 10-100 \mathrm{~Bq}$ range), ${ }^{152} \mathrm{Eu}(\mathrm{III}, \quad 10-100 \mathrm{~Bq}$ 
range), ${ }^{244} \mathrm{Cm}$ (III, $10-100 \mathrm{~Bq}$ range), ${ }^{232} \mathrm{U}(\mathrm{VI}),{ }^{239} \mathrm{Pu}(\mathrm{IV})$ and ${ }^{237} \mathrm{~Np}(\mathrm{IV}, 10 \mathrm{~Bq}$ each isotope) were added and the solution readjusted to $4 \mathrm{M} \mathrm{HCl}$. N.B. For high level Fe/Ca/Al matrices, the matrix was generated as above with the addition of $\sim 10 \mathrm{mg} \mathrm{mL}^{-1} \mathrm{Fe}(\mathrm{III})$ or $\mathrm{Ca}(\mathrm{II})$ or $\mathrm{Al}(\mathrm{III})$, added as chloride.

Anion exchange/extraction chromatography: The matrix was evaporated to dryness twice times with addition of conc. $\mathrm{HCl}(2 \mathrm{~mL})$. The residue was dissolved in the minimum volume of conc. $\mathrm{HCl}$. A $50 \mathrm{~mm} \times 4 \mathrm{~mm}$ anion exchange column (Bio-Rad AG1-X8, 200-400 mesh) was conditioned with the following procedure: sodium bromate $(5 \mathrm{mg})$ in conc. $\mathrm{HCl}(5 \mathrm{~mL})$ was added. The column was washed with conc. $\mathrm{HCl}(4 \mathrm{~mL})$ then aq. $\mathrm{HCl}(5 \mathrm{~mL}$, $1 \mathrm{M})$ and conc. $\mathrm{HCl}(5 \mathrm{~mL})$. The sample was loaded using conc. $\mathrm{HCl}$ to wash $(2 \mathrm{~mL}) . \mathrm{Am}(\mathrm{III})$, lanthanides(III), $\mathrm{Cs}(\mathrm{I}), \mathrm{Be}(\mathrm{II})$ were eluted with conc. $\mathrm{HCl}(6 \mathrm{~mL}) . \mathrm{Pu}(\mathrm{III})$ was eluted with conc. $\mathrm{HCl}$ containing $1 \% \mathrm{v} / \mathrm{v} \mathrm{HI}(5 \mathrm{~mL})$. $\mathrm{Co}, \mathrm{Zr}, \mathrm{Np}$ (IV) were eluted with $\mathrm{HCl}(5 \mathrm{~mL}, 4 \mathrm{M})$. Mo, Fe, $\mathrm{U}(\mathrm{VI})$ were eluted with $\mathrm{HCl}(3 \mathrm{~mL}, 1 \mathrm{M})$ followed by $\mathrm{HCl}$ ( $3 \mathrm{~mL}, 0.5 \mathrm{M})$. Cd and $\mathrm{Ag}$ were eluted using deionised water $(1 \mathrm{~mL})$ followed by $\mathrm{NH}_{4} \mathrm{OH}(4 \mathrm{~mL}, 1 \mathrm{M})$.

Liquid-liquid Am/Cm separation procedure: Each ligand was dissolved in $1 \mathrm{~mL}$ of 1-octanol to its chosen concentration, mixed for $5 \mathrm{~min}$ and sonicated for $1 \mathrm{~min}$. The organic phase was contacted with the Am-containing fraction from chromatography for $90 \mathrm{~min}$ with vortex mixing. The sample was centrifuged at $1788 \mathrm{~g} / 4000 \mathrm{rpm}$ for $5 \mathrm{~min}$ and the phases separated. The aqueous phase was analysed by gamma spectroscopy and then evaporated to dryness, dissolved in aqueous $\mathrm{HNO}_{3}(2 \% \mathrm{w} / \mathrm{v}$, VWR, AnalaR NORMAPUR ${ }^{\circledR}$ grade) and diluted by a factor of 10000 for ICP-MS analysis. The organic phase was back-extracted with $0.1 \mathrm{M} \mathrm{HCl}$ for $90 \mathrm{~min}$ and the resulting aqueous solution electroplated as below. The U, Pu and Np-containing fractions from chromatography were also electroplated for alpha spectrometry.

Electrodeposition procedure: The solution to be electroplated was evaporated to dryness. Aqueous $\mathrm{NaHSO}_{4}$ $(5 \%, 2.5 \mathrm{~mL})$, water $(2 \mathrm{~mL})$ and aqueous $\mathrm{Na}_{2} \mathrm{SO}_{4}(15 \%$, $5 \mathrm{~mL}$ ) were added to the residue and heated, the solution was transferred to an electrodeposition cell using water $(3 \mathrm{~mL})$ and $\left(\mathrm{NH}_{4}\right)_{2} \mathrm{C}_{2} \mathrm{O}_{4}(160 \mathrm{mM}, 1 \mathrm{~mL})$ was added. The current was set to $0.5 \mathrm{~A}$ for $5 \mathrm{~min}$, then $0.75 \mathrm{~A}$ for $60 \mathrm{~min}$. $1 \mathrm{~min}$ before the end of electrodeposition, aqueous $\mathrm{KOH}$ $(25 \%, 2 \mathrm{~mL})$ was added. The solution was decanted off and the cell washed with aqueous $\mathrm{NH}_{4} \mathrm{OH}(5 \%, 2 \mathrm{~mL})$. The plate was rinsed with $5 \% \mathrm{NH}_{4} \mathrm{OH}$, ethanol and acetone before drying in the air.

\section{Results and discussion}

\subsection{Ligand selection}

The family of four ligands used in this study was based around $\mathrm{CyMe}_{4}$-BTPhen $\mathbf{1}$, previously shown by us to separate $\mathrm{Am} / \mathrm{Eu}$ with a separation factor of up to 400 [9]. We therefore identified $\mathrm{CyMe}_{4}$-BTPhen as a potential ligand for the separation of Am from aqueous matrices containing actinides, lanthanides and matrix elements. The ligand can be recycled for repeat use, and adheres to the CHON principle such that it can be safely incinerated after use, avoiding the generation of toxic waste. From this, we identified 3 related ligands with similar properties which could be applied to selective extraction of Am/Cm: CABTPhen 2, CA-BTP 3 and $\mathrm{CyMe}_{4}$-BTBP 4 (Figure 2). These ligands encompass the most promising triazine motifs previously used in Am/Eu separation (BTPs, BTPhens and BTBPs). We also attempted to select compounds which could easily be obtained in an analytical laboratory setting i.e. easily synthesised. In particular, we were interested in ligands containing the camphor (CA) group as this is resistant to hydrolysis/radiolysis [12] and the camphor diketone required for synthesis is commercially available (unlike $\mathrm{CyMe}_{4}$ diketone). CA-BTP $\mathbf{3}$ was chosen as a potential ligand as it is synthesised in only two steps and has increased solubility in 1-octanol compared to BTBPs and BTPhens [9]. CyMe ${ }_{4}$ BTBP 4 is the current benchmark ligand for the proposed SANEX process and has been widely applied to Am (III) extraction in recent years $[8,10]$.

\subsection{Application of ligands to $\mathrm{Am} / \mathrm{Cm}$ extraction from simulated nuclear forensic matrices}

The four ligands were synthesised as previously reported [12-14]. Based on previously reported work, our work with the BTPhen ligands and preliminary $\mathrm{Am} / \mathrm{Eu}$ (III) separations carried out as part of this investigation, we determined a number of parameters for the $\mathrm{Am} / \mathrm{Cm}$ extraction. The organic phase selected for the separation was 1-octanol, since alternative solvents such as cyclohexanone were shown to cause phase separation issues in initial tests with the nuclear forensic matrix. The aqueous phase selected was $4 \mathrm{M} \mathrm{HCl}$ as this would be compatible with further separation processes e.g. for the lanthanides. Acid concentrations in the range 2-4 M $\left(\mathrm{HCl}\right.$ or $\mathrm{HNO}_{3}$ ) would be suitable for Am extraction from previous $\mathrm{Am} / \mathrm{Eu}$ separation work[9]. We avoided the addition of phase modifiers in this work as this could 
Table 1: Recoveries of eluted matrix elements from AGI-X8 column chromatography from analysis by alpha spectrometry and ICP-MS. (N.B. error calculated from instrument and method error plus one sigma, sample data averaged from $n=20$ analysis of all run in triplicate).

\begin{tabular}{lrrrrrrr}
\hline & \multicolumn{7}{c}{ Isotope } \\
\cline { 2 - 8 } & ${ }^{90} \mathrm{Zr}$ & ${ }^{95} \mathrm{Mo}$ & ${ }^{107} \mathrm{Ag}$ & ${ }^{111} \mathrm{Cd}$ & ${ }^{232} \mathrm{U}$ & ${ }^{239} \mathrm{Pu}$ & ${ }^{237} \mathrm{~Np}$ \\
\hline Recovery \pm & 97.21 & 95.23 & 99.74 & 92.01 & 96.76 & 97.24 & 96.08 \\
Error/\% & \pm 2.01 & \pm 1.99 & \pm 1.05 & \pm 1.35 & \pm 3.21 & \pm 2.12 & \pm 0.71 \\
\hline
\end{tabular}

increase co-extraction of particular elements such as lanthanides, and also complicate back extracted. (N.B. Separation factors $(\mathrm{Am} / \mathrm{Eu})$ were determined to be similar to those reported above, for distribution ratio data and $\mathrm{HCl} / \mathrm{HNO}_{3}$ extraction data please see $\left.[9,12,13]\right)$.

The simulated nuclear forensic matrix was designed to simulate an aqueous acidic matrix obtained from a nuclear debris sample after pre-treatment (e.g. total dissolution). The matrix was generated by dissolution of $\mathrm{Be}(\mathrm{II}), \mathrm{Mo}(\mathrm{VI}), \mathrm{Cs}(\mathrm{I}), \mathrm{Ce}, \mathrm{Pr}, \mathrm{Nd}, \mathrm{Sm}, \mathrm{Tb}, \mathrm{Y}$ (all III), $\mathrm{Zr}(\mathrm{IV}), \operatorname{Ag}(\mathrm{I}), \mathrm{Cd}(\mathrm{II}), \mathrm{Sr}(\mathrm{II})$ and $\mathrm{Ba}(\mathrm{II})$ and all the lanthanides (except $\mathrm{Pm}$ and $\mathrm{Eu}$ ) as chlorides in $4 \mathrm{M} \mathrm{HCl}$ solution. The target concentration for each stable element was $\sim 1 \mathrm{mg} \mathrm{mL}{ }^{-1}$ of metal. Tracers of ${ }^{241} \mathrm{Am}$ (III), ${ }^{152} \mathrm{Eu}(\mathrm{III})$, ${ }^{244} \mathrm{Cm}(\mathrm{III}),{ }^{232} \mathrm{U}(\mathrm{VI}),{ }^{239} \mathrm{Pu}(\mathrm{IV})$ and ${ }^{237} \mathrm{~Np}(\mathrm{IV})$ were added and the solution adjusted to $4 \mathrm{M} \mathrm{HCl}$. The concentration of each element in the representative matrix before $\mathrm{Am} / \mathrm{Cm}$ (III) extraction was determined by ICP-MS.
The simulated nuclear forensic matrix was then subjected to AGI-X8 anion exchange chromatography (chloride form) to separate the major/minor actinides (U(VI), $\mathrm{Pu}(\mathrm{IV}), \mathrm{Np}(\mathrm{IV})$ ) and yield an $\mathrm{Am} / \mathrm{Cm}$ (III) containing fraction which would be used in the subsequent triazine ligand extraction. The major actinides were analysed by alpha spectrometry and recoveries were found to be $>94 \%$ (Table 1). Recoveries of the co-eluting matrix elements (Zr, Mo, Ag, Cd) were determined by ICP-MS of the relevant fractions and found to be $>91 \%$ (Table 1). This first step of the overall separation process allows for immediate separation of the major actinides, allowing their quantification (electrodeposition and alpha spectrometry) to be performed concurrently with the subsequent Am/Cm(III) separation. This would ensure data is collected in a timely manner, which is of vital importance in nuclear forensics.

The $\mathrm{Am} / \mathrm{Cm}$ (III) fraction was then subjected to liquid-liquid separation using each of the four ligands in 1-octanol/4 M HCl. The phases were vortex mixed for $90 \mathrm{~min}$, this was based on the time required for $\mathrm{Am} / \mathrm{Eu}$ (III) extraction using $\mathrm{CyMe}_{4} \mathrm{BTPhen}$ in our previous work. The resulting aqueous phases were analysed by gamma spectrometry (to determine Eu) and ICP-MS analysis (to determine matrix elements). The organic phase was backextracted with $0.1 \mathrm{M} \mathrm{HCl}$ for $1 \mathrm{~h}$ (determined in preliminary work to be adequate for consistent back extraction) and the resulting aqueous phase was analysed by alpha spectrometry for $\mathrm{Am} / \mathrm{Cm}$. Extraction of Am and $\mathrm{Cm}$ (III) was seen with all four ligands (Table 2). $\mathrm{CyMe}_{4} \mathrm{BTPhen}$ extracted the highest quantity of Am(III)

Table 2: Recoveries of eluted matrix elements for AGI-X8 column chromatography/triazine ligand separation from analysis by alpha spectrometry, gamma spectroscopy and ICP-MS. (N.B. error calculated from instrument and method error plus one sigma, sample data averaged from $n=20$ analysis run in triplicate, all calibrated against a range of standards in the concentration ranges above).

\begin{tabular}{|c|c|c|c|c|c|c|c|}
\hline \multirow[b]{2}{*}{ Ligand } & \multicolumn{7}{|c|}{ Isotope recovery \pm error $/ \%$} \\
\hline & ${ }^{241} \mathrm{Am}$ & ${ }^{244} \mathrm{Cm}$ & ${ }^{152} \mathrm{Eu}$ & ${ }^{9} \mathrm{Be}$ & ${ }^{88} \mathrm{Sr}$ & ${ }^{89} \mathrm{Y}$ & ${ }^{133} \mathrm{Cs}$ \\
\hline $\mathrm{CyMe}_{4-}$ BTPhen & $96.4 \pm 2.3$ & $94.1 \pm 2.2$ & $95.0 \pm 4.1$ & $98.2 \pm 2.2$ & $99.7 \pm 0.7$ & $98.7 \pm 2.4$ & $100.1 \pm 2.0$ \\
\hline CA-BTP & $70.0 \pm 2.2$ & $65.0 \pm 2.3$ & $90.8 \pm 6.2$ & $98.2 \pm 2.6$ & $99.2 \pm 2.1$ & $93.2 \pm 0.5$ & $91.9 \pm 2.5$ \\
\hline $\mathrm{CyMe}_{4}$ BTBP & $85.7 \pm 2.6$ & $95.2 \pm 2.8$ & $95.3 \pm 3.9$ & $99.8 \pm 1.0$ & $94.5 \pm 1.1$ & $99.8 \pm 1.9$ & $95.2 \pm 0.6$ \\
\hline \multirow[t]{2}{*}{ CA-BTPhen } & $43.5 \pm 2.7$ & $56.1 \pm 2.6$ & $93.8 \pm 5.6$ & $99.9 \pm 0.8$ & $92.9 \pm 3.1$ & $92.2 \pm 0.5$ & $101.3 \pm 2.1$ \\
\hline & ${ }^{137} \mathrm{Ba}$ & ${ }^{139} \mathrm{La}$ & ${ }^{140} \mathrm{Ce}$ & ${ }^{141} \mathrm{Pr}$ & ${ }^{146} \mathrm{Nd}$ & ${ }^{147} \mathrm{Sm}$ & ${ }^{157} \mathrm{Gd}$ \\
\hline $\mathrm{CyMe}_{4-}$ BTPhen & $99.0 \pm 1.0$ & $94.4 \pm 0.5$ & $95.2 \pm 2.1$ & $99.6 \pm 1.7$ & $100.6 \pm 2.1$ & $102.1 \pm 1.0$ & $99.2 \pm 1.5$ \\
\hline CA-BTP & $99.6 \pm 0.8$ & $93.7 \pm 1.0$ & $96.4 \pm 1.2$ & $100.3 \pm 1.0$ & $97.7 \pm 1.0$ & $94.3 \pm 0.7$ & $99.1 \pm 0.3$ \\
\hline $\mathrm{CyMe}_{4} \mathrm{BTBP}$ & $101.0 \pm 1.1$ & $102.1 \pm 2.8$ & $100.0 \pm 1.3$ & $99.6 \pm 0.7$ & $98.9 \pm 1.1$ & $107.2 \pm 9.7$ & $100.1 \pm 0.7$ \\
\hline \multirow[t]{2}{*}{ CA-BTPhen } & $91.9 \pm 0.3$ & $94.7 \pm 1.0$ & $88.7 \pm 0.6$ & $92.5 \pm 0.7$ & $94.7 \pm 0.6$ & $99.3 \pm 0.3$ & $99.7 \pm 0.4$ \\
\hline & ${ }^{159} \mathrm{~Tb}$ & ${ }^{163}$ Dy & ${ }^{165} \mathrm{Ho}$ & ${ }^{166} \mathrm{Er}$ & ${ }^{169} \mathrm{Tm}$ & ${ }^{172} \mathrm{Yb}$ & ${ }^{175} \mathrm{Lu}$ \\
\hline $\mathrm{CyMe}_{4-}$ BTPhen & $94.6 \pm 1.2$ & $94.3 \pm 1.5$ & $98.9 \pm 0.5$ & $91.6 \pm 1.0$ & $97.7 \pm 0.3$ & $98.9 \pm 1.2$ & $95.1 \pm 1.2$ \\
\hline CA-BTP & $97.8 \pm 0.6$ & $98.2 \pm 1.1$ & $98.9 \pm 0.7$ & $97.6 \pm 0.7$ & $101.7 \pm 0.7$ & $97.8 \pm 0.5$ & $91.3 \pm 2.1$ \\
\hline $\mathrm{CyMe}_{4}$ BTBP & $97.4 \pm 0.2$ & $100.5 \pm 1.3$ & $98.9 \pm 0.6$ & $99.2 \pm 1.2$ & $99.3 \pm 0.2$ & $100.5 \pm 1.6$ & $100.3 \pm 0.9$ \\
\hline CA-BTPhen & $98.2 \pm 0.2$ & $99.7 \pm 0.5$ & $98.7 \pm 0.4$ & $95.8 \pm 0.4$ & $97.4 \pm 0.4$ & $99.9 \pm 0.4$ & $102.4 \pm 2.2$ \\
\hline
\end{tabular}


Furnaced and leached complex nuclear forensic sample - aqueous matrix of $\mathrm{Be}, \mathrm{Sr}, \mathrm{Y}, \mathrm{Zr}, \mathrm{Ag}, \mathrm{Cs}, \mathrm{Ba}, \mathrm{Ln}, \mathrm{U}, \mathrm{Np}, \mathrm{Pu}, \mathrm{Am}, \mathrm{Cm}$ (\& $\mathrm{Fe} / \mathrm{Ca} / \mathrm{Al})$

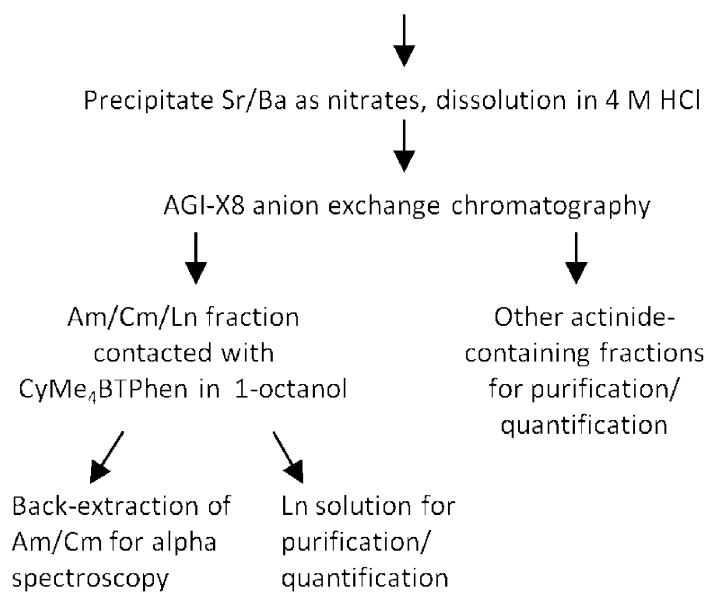

Fig. 3: Method for extraction of $\mathrm{Am} / \mathrm{Cm}$ from complex nuclear forensic sample using $\mathrm{CyMe}_{4}$ BTPhen (this work).

over $90 \mathrm{~min}(96.0 \pm 2.3 \%)$ and also had high extraction of $\mathrm{Cm}$ (III, $94.1 \pm 2.2 \%)$. The other three ligands extracted $\mathrm{Am} / \mathrm{Cm}$ (III) to a lesser extent over $90 \mathrm{~min}$, but when the mixing time was increased to $3 \mathrm{~h}$ these recoveries were $>90 \%$. Over the 90 minute separations, $\mathrm{Eu}$ (III) extraction was minimal compared to $\mathrm{Am} / \mathrm{Cm}$ (III) extraction. ICP-MS analysis showed high recovery of matrix elements including all lanthanides (III, $>88 \%$, Table 2 ) showing that the method allows for high decontamination (and $\mathrm{SF}>100$ for each ligand with respect to the lanthanides) for $\mathrm{Am} / \mathrm{Cm}$ with respect to these elements.

Overall, the combined AG1-X8/triazine ligand separation procedure developed allows for the quantification and determination of the major actinides $(\mathrm{U}$, $\mathrm{Pu}, \mathrm{Np}$ ) and $\mathrm{Am} / \mathrm{Cm}(\mathrm{III})$ within 2 days. In addition, a lanthanide containing fraction is obtained which can be subjected to further separation. From the results obtained, $\mathrm{CyMe}_{4} \mathrm{BTPhen}$ is the most promising ligand for a rapid extraction ( $<90 \mathrm{~min}$ ) of $\mathrm{Am} / \mathrm{Cm}$. We therefore propose a method, as shown in Figure 3, in which this ligand is utilised for $\mathrm{Am} / \mathrm{Cm}$ (III) extraction from a $\mathrm{Am} / \mathrm{Cm} / \mathrm{Ln}$ solution post AG1-X8 chromatography.

\subsection{Am/ $\mathrm{Cm}$ extraction from simulated nuclear forensic matrices in the presence of $\mathrm{Fe}, \mathrm{Ca}$ and $\mathrm{Al}$}

Complex nuclear forensic samples may be derived from any origin, but $\mathrm{Fe}, \mathrm{Ca}$ and $\mathrm{Al}$ are often present in high amounts as these elements are found in high amounts in soils, cements and metals. Typically samples with high levels of these elements require additional purification to avoid interference with separation processes. We wished to assess the impact of $\left(10 \mathrm{mg} \mathrm{mL}^{-1}\right) \mathrm{Fe}, \mathrm{Ca}$ and $\mathrm{Al}$ on our $\mathrm{Am} / \mathrm{Cm}$ separation procedure. We therefore generated three matrices by separate addition of $\mathrm{Fe}(\mathrm{III}), \mathrm{Ca}(\mathrm{II})$ and $\mathrm{Al}(\mathrm{III})$ in chloride form to the matrix described above, and repeated the investigation with each of the four ligands. With sampling we felt that these levels would simulate matrix element interferences.

Recovery of U(VI), Np(IV), Pu(III), Zr(IV), Mo(VI), $\mathrm{Ag}(\mathrm{I})$ and $\mathrm{Cd}(\mathrm{II})$ from AG1-X8 chromatography was unaffected by high levels of $\mathrm{Fe}, \mathrm{Ca}$ or $\mathrm{Al}$, as expected. Iron was also removed in this part of the process (co-eluted with $\mathrm{U}$, separated by precipitation), with a recovery $>93 \%$ by ICP-MS across all experiments (errors from SD from $n=14$ replicates $<3.0 \%$ in all experiments). After extraction of $\mathrm{Am} / \mathrm{Cm}$ by the four ligands, the remaining elements were determined as previously, also $\mathrm{Ca}$ and $\mathrm{Al}$ were determined by ICP-MS (Table 3). Am/Cm and Eu extraction was unaffected for all ligands in the presence of $\mathrm{Ca}$ and $\mathrm{Al}$ except for $\mathrm{CyMe}_{4} \mathrm{BTBP}$ in the presence of Ca when $\mathrm{Am} / \mathrm{Cm}$ extraction was reduced by $\sim 15 \%-20 \%$. Recovery of matrix elements including lanthanides was not greatly affected by the presence of high level Ca or Al. From ICP-MS analysis, the recoveries of $\mathrm{Ca}$ and $\mathrm{Al}$ were also determined from each separation. Apart from CA-BTPhen, all ligands were seen to co-extract both $\mathrm{Al}$ and $\mathrm{Ca}$ to some extent. In particular, for $\mathrm{CyMe}_{4} \mathrm{BTBP}$, Ca was extracted $(\sim 15 \%)$ and $\mathrm{Am} / \mathrm{Cm}$ extraction decreased, meaning that high $\mathrm{Am} / \mathrm{Cm}$ recovery could not be obtained even over a $3 \mathrm{~h}$ extraction. However, in cases where $\mathrm{Ca}(\mathrm{II}) / \mathrm{Al}$ (III) co-extraction does not affect $\mathrm{Am} / \mathrm{Cm}$ (III) separation it will affect electrodeposition of the sample. In addition, pre-treatment steps could be utilised to remove the high level elements, but this could be at the expense of process time.

From investigation of the normal and high level Fe, $\mathrm{Ca}$ and $\mathrm{Al}$ matrices, we concluded that $\mathrm{CyMe}_{4} \mathrm{BTPhen}$ is the most suitable ligand for $\mathrm{Am} / \mathrm{Cm}$ (III) extraction from complex nuclear forensic samples based on the nearquantitative $\mathrm{Am} / \mathrm{Cm}$ (III) extraction achieved in $90 \mathrm{~min}$. In addition, high levels of $\mathrm{Ca}$ and $\mathrm{Al}$ did not affect the $\mathrm{Am} / \mathrm{Cm}$ extraction by this ligand. To fully determine the ability of $\mathrm{CyMe}_{4}$ BTPhen to extract Am/Cm from complex nuclear forensic matrices, we then wished to perform the extraction in the presence of all elements i.e. without prior AG1-X8 chromatography. 
Table 3: Recoveries of eluted matrix elements for high Ca (a) and high Al (b) from AGI-X8 column chromatography from analysis by alpha spectrometry, gamma spectroscopy and ICP-MS. (N.B. error calculated from instrument and method error plus one sigma, sample data averaged from $n=20$ analysis run in triplicate, all calibrated against a range of standards in the concentration ranges above).

(a) Isotope recovery \pm error $/ \%$

\begin{tabular}{|c|c|c|c|c|c|c|c|c|c|c|c|}
\hline Ligand & Am & ${ }^{4} \mathrm{Cm}$ & ${ }^{152} \mathrm{Eu}$ & ${ }^{9} \mathrm{Be}$ & ${ }^{88} \mathrm{Sr}$ & ${ }^{89} \mathrm{Y}$ & ${ }^{43} \mathrm{Ca}$ & ${ }^{133} \mathrm{Cs}$ & ${ }^{137} \mathrm{Ba}$ & ${ }^{139} \mathrm{La}$ & 140 \\
\hline $\mathrm{CyMe}_{4}$-BTPhen & $95.9 \pm 2.4$ & $93.9 \pm 2.4$ & $95.2 \pm 6.5$ & $99.2 \pm 2.1$ & $98.8 \pm 3.2$ & $95.7 \pm 1.9$ & $96.4 \pm 1.2$ & $107.6 \pm 1.2$ & $98.3 \pm 1.0$ & $98.9 \pm 1.0$ & $2.3 \pm 1$ \\
\hline CA-BTP & $68.0 \pm 2.6$ & $63.1 \pm 2.6$ & $90.3 \pm 6.6$ & $00.0 \pm 1.6$ & $94.6 \pm 1.5$ & $100.8 \pm 3.0$ & $91.8 \pm 3.2$ & $99.3 \pm 1.8$ & $39.6 \pm 2.2$ & $92.5 \pm 1.0$ & $7.2 \pm 1$ \\
\hline $\mathrm{CyMe}_{4}$-BTBP & $68.6 \pm 2.3$ & $73.6 \pm 2.9$ & $91.4 \pm 5.7$ & $99.7 \pm 2.5$ & $95.2 \pm 0.3$ & $99.7 \pm 0.7$ & $85.1 \pm 1.2$ & $95.7 \pm 0.7$ & $93.8 \pm 1.1$ & $97.1 \pm 1.0$ & $6.3 \pm 0$ \\
\hline \multirow[t]{2}{*}{ CA-BTPhen } & $.5 \pm 2.4$ & $43.4 \pm 2.2$ & $5.3 \pm 6.8$ & $99.7 \pm 1.3$ & $93.5 \pm 1.2$ & $102.8 \pm 0.9$ & $103.0 \pm 2.3$ & $102.3 \pm 2.6$ & $100.5 \pm 1.5$ & $102.9 \pm 1.2$ & $00.9 \pm 0$ \\
\hline & ${ }^{141} \mathrm{Pr}$ & ${ }^{146} \mathrm{Nd}$ & ${ }^{147} \mathrm{Sm}$ & ${ }^{157} \mathrm{Gd}$ & ${ }^{159} \mathrm{~Tb}$ & ${ }^{163} \mathrm{Dy}$ & ${ }^{165} \mathrm{Ho}$ & ${ }^{166} \mathrm{Er}$ & ${ }^{169} \mathrm{Tm}$ & ${ }^{172} \mathrm{Yb}$ & ${ }^{175} \mathrm{I}$ \\
\hline $\mathrm{Me}_{4}$-BTPhen & $96.9 \pm 0.5$ & $99.2 \pm 0.5$ & $2.1 \pm 2.4$ & $103.7 \pm 3.9$ & $102.9 \pm 3.1$ & $100.3 \pm 1.0$ & $96.8 \pm 0.8$ & $100.5 \pm 0.7$ & $100.3 \pm 0.7$ & 0.8 & I0 \\
\hline CA-BTP & $91.3 \pm 1.1$ & $93.0 \pm 0.9$ & $.0 \pm 1.6$ & $.4 \pm 0.6$ & $95.3 \pm 1.3$ & $96.9 \pm 1.4$ & $.8 \pm 1.7$ & $3.1 \pm 1.0$ & $100.7 \pm 1.3$ & 99.9 & \pm 2 \\
\hline $\mathrm{CyMe}_{4}$-BTBP & $96.0 \pm 1.9$ & $93.3 \pm 1.4$ & $100.4 \pm 1.6$ & $94.2 \pm 2.4$ & $100.1 \pm 1.4$ & $94.2 \pm 0.5$ & $96.4 \pm 1.1$ & $89.5 \pm 1.4$ & $97.2 \pm 0.7$ & $87.0 \pm 3.0$ & $101.1 \pm 2$ \\
\hline A-BTPhen & $.7 \pm 0.8$ & $00.1 \pm 1.6$ & $0.5 \pm 0.7$ & $9.0 \pm 1.6$ & $99.9 \pm 0.4$ & $102.3 \pm 2.5$ & \pm 2.7 & $99.0 \pm 0.5$ & 0.5 & $99.3 \pm 0.5$ & $1.9 \pm 2$ \\
\hline (b) & \multicolumn{11}{|c|}{ Isotope recovery \pm error $/ \%$} \\
\hline gand & ${ }^{41} \mathrm{Am}$ & ${ }^{244} \mathrm{Cm}$ & ${ }^{152} \mathrm{Eu}$ & ${ }^{9} \mathrm{Be}$ & ${ }^{88} \mathrm{Sr}$ & ${ }^{89} \mathrm{Y}$ & ${ }^{27} \mathrm{Al}$ & ${ }^{133} \mathrm{Cs}$ & ${ }^{137} \mathrm{Ba}$ & ${ }^{139} \mathrm{La}$ & ${ }^{140} \mathrm{C}$ \\
\hline $\mathrm{Me}_{4}$-BTPhen & $94.8 \pm 2.1$ & $97.8 \pm 2.1$ & $95.0 \pm 6.2$ & $3 \pm 1.3$ & $98.4 \pm 0.7$ & \pm 1.9 & \pm 2.2 & $92.7 \pm 1.2$ & $92.1 \pm 1.0$ & 1.1 & $97.6 \pm 1$ \\
\hline A-BTP & $65.4 \pm 2.7$ & $63.6 \pm 2.7$ & $91.3 \pm 5.9$ & $2 \pm 1.6$ & $8 \pm 1.3$ & $100.6 \pm 1.4$ & $5 \pm 1.6$ & $91.8 \pm 1.8$ & $=1.8$ & 97.5 & $96.0 \pm 1$ \\
\hline $\mathrm{CyMe}_{4}$-BTBP & \pm 2.3 & \pm 2.7 & $94.6 \pm 6.0$ & 0.7 & \pm 0.8 & \pm 1.1 & $.3 \pm 2.2$ & $98.8 \pm 0.7$ & $87.3 \pm 1.1$ & $91.5 \pm 1.0$ & $86.2 \pm 0$ \\
\hline \multirow[t]{2}{*}{ CA-BTPhen } & $43.5 \pm 2.7$ & $53.1 \pm 2.7$ & $1.4 \pm 5.9$ & $99.8 \pm 0.9$ & $100.0 \pm 0.6$ & $3.6 \pm 0.9$ & $100.5 \pm 0.8$ & $102.9 \pm 3.2$ & $100.6 \pm 1.5$ & $101.7 \pm 1.8$ & $95.6 \pm 0$ \\
\hline & ${ }^{141} \operatorname{Pr}$ & ${ }^{146} \mathrm{Nd}$ & ${ }^{147} \mathrm{Sm}$ & ${ }^{157} \mathrm{Gd}$ & ${ }^{159} \mathrm{~Tb}$ & ${ }^{163}$ Dy & ${ }^{165} \mathrm{Ho}$ & ${ }^{166} \mathrm{Er}$ & ${ }^{169} \mathrm{Tm}$ & ${ }^{172} \mathrm{Yb}$ & ${ }^{175}$ \\
\hline $\mathrm{Me}_{4}$-BTPhen & $101.8 \pm 2.1$ & $.0 \pm 0.3$ & $96.5 \pm 0.5$ & $7 \pm 0.6$ & $0 \pm 0.3$ & $.9 \pm 1.0$ & $92.8 \pm 0.8$ & $9 \pm 0.7$ & $100.2 \pm 0.8$ & 0.5 & 20.0 \\
\hline CA-BTP & $96.7 \pm 1.1$ & $94.0 \pm 0.9$ & $93.2 \pm 1.0$ & $95.1 \pm 0.5$ & $92.7 \pm 1.3$ & $93.2 \pm 1.4$ & $97.3 \pm 1.7$ & $94.9 \pm 1.0$ & $97.9 \pm 2.0$ & $102.2 \pm 1.9$ & $101.3 \pm 1$ \\
\hline $\mathrm{CyMe}_{4}$-BTBP & $89.3 \pm 1.4$ & $91.6 \pm 1.4$ & $94.8 \pm 1.6$ & $95.8 \pm 1.2$ & $94.2 \pm 1.4$ & $95.3 \pm 0.5$ & $98.3 \pm 1.1$ & $91.5 \pm 1.4$ & $93.5 \pm 0.6$ & $99.2 \pm 0.6$ & $99.9 \pm C$ \\
\hline CA-BTPhen & $99.1 \pm 0.8$ & $98.1 \pm 0.9$ & $95.2 \pm 0.7$ & $99.6 \pm 0.3$ & $98.2 \pm 0.4$ & $100.4 \pm 0.5$ & $101.0 \pm 1.8$ & $99.4 \pm 0.5$ & $99.5 \pm 0.5$ & $97.3 \pm 0.5$ & $91.4 \pm C$ \\
\hline
\end{tabular}

\subsection{Am/Cm extraction from simulated nuclear forensic matrices by $\mathrm{CyMe}_{4}$ BTPhen without prior chromatography}

$\mathrm{CyMe}_{4} \mathrm{BTPhen}$ was used to extract $\mathrm{Am} / \mathrm{Cm}$ (III) in the manner outlined above from the normal matrix and matrices with high level $\mathrm{Fe}, \mathrm{Ca}$ and $\mathrm{Al}$, without the AG1-X8 chromatography method. Am/Cm(III) extraction was unaffected with recoveries $>90 \%$ within 90 min, with minimal extraction of Eu(III) (Table 4). Recoveries determined for matrix elements including lanthanides by ICP-MS were $>88 \%$, including $\mathrm{Ag}(\mathrm{I})$ and $\mathrm{Mo}(\mathrm{VI})$ which were removed by AG1-X8 in our previous investigation. A notable exception is $\mathrm{Cd}(\mathrm{II})$, which was co-extracted from all matrices by $\mathrm{CyMe}_{4} \mathrm{BTPhen}$ (recoveries 35\%-45\% depending on matrix. This can be rationalised as the closely related $\mathrm{N}$-donor ligand 2,9-di(2-pyridyl)-1,10-phenanthroline has been shown to be a highly selective sensor of Cd(II) [16]. Although in our proposed AG1-X8/CyMe ${ }_{4}$ BTPhen extraction procedure this would not pose a problem as $\mathrm{Cd}$ would be removed in the chromatography step, $\mathrm{Cd}$ (II) can also be selectively removed from the Am/Cm solution using known separation techniques [17]. For the high level Fe, $\mathrm{Ca}$ and $\mathrm{Al}$ matrices, recoveries of $\mathrm{Fe}(\mathrm{III}), \mathrm{Ca}(\mathrm{II})$ and $\mathrm{Al}(\mathrm{III})$ were $>86 \%$ by ICP-MS (Table 4 ).

After separation, the aqueous phase was subjected to chromatography to separate U (VI), Pu (III) and Np (IV) for determination by alpha spectrometry. Recoveries $>90 \%$ were obtained for the major actinides indicating presence of these elements does not affect $\mathrm{Am} / \mathrm{Cm}$ (III) extraction. Overall, the initial method of AGI-X8/CyMe ${ }_{4}$ BTPhen separation would be preferred in order to simplify the matrix and avoid Cd (II) co-extraction, however this investigation shows that $\mathrm{CyMe}_{4} \mathrm{BTPhen}$ may be used to extract $\mathrm{Am} / \mathrm{Cm}$ in the presence of many competing ions with minimal co-extraction.

\section{Conclusions}

We have developed a selective radiochemical separation process for $\mathrm{Am} / \mathrm{Cm}$ (III) for application to complex nuclear forensics samples using AG1-X8 chromatography followed by a triazine ligand extraction. In our procedure, purification and quantification of all major actinides can be achieved in $>2$ days, which would be valuable in a nuclear 


\begin{tabular}{|c|c|c|c|c|c|c|}
\hline \multirow[b]{2}{*}{ Matrix } & \multicolumn{6}{|c|}{ Ligand: $\mathrm{CyMe}_{4} \mathrm{BTPhen}$, Isotope recovery \pm error $/ \%$} \\
\hline & ${ }^{241} \mathrm{Am}$ & ${ }^{244} \mathrm{Cm}$ & ${ }^{152} \mathrm{Eu}$ & ${ }^{56} \mathrm{Fe}$ & ${ }^{43} \mathrm{Ca}$ & ${ }^{27} \mathrm{Al}$ \\
\hline $\mathrm{Fe}(\mathrm{III})$ & $91.3 \pm 2.3$ & $90.2 \pm 2.3$ & $95.1 \pm 5.1$ & $100.1 \pm 3.1$ & - & - \\
\hline $\mathrm{Ca}(\mathrm{II})$ & $90.9 \pm 2.4$ & $91.0 \pm 2.5$ & $100.3 \pm 4.1$ & - & $91.0 \pm 0.4$ & - \\
\hline \multirow[t]{2}{*}{$\operatorname{Al}(I I I)$} & $90.1 \pm 2.1$ & $90.5 \pm 2.2$ & $94.3 \pm 4.5$ & - & - & $88.9 \pm 2.5$ \\
\hline & ${ }^{9} \mathrm{Be}$ & ${ }^{88} \mathrm{Sr}$ & ${ }^{89} \mathrm{Y}$ & ${ }^{95} \mathrm{Mo}$ & ${ }^{107} \mathrm{Ag}$ & ${ }^{111} \mathrm{Cd}$ \\
\hline $\mathrm{Fe}(\mathrm{III})$ & $99.1 \pm 4.4$ & $100.5 \pm 1.6$ & $86.6 \pm 1.4$ & $100.0 \pm 0.4$ & $100.8 \pm 0.8$ & $44.7 \pm 0.4$ \\
\hline $\mathrm{Ca}(\mathrm{II})$ & $98.1 \pm 1.4$ & $98.8 \pm 3.7$ & $95.7 \pm 1.1$ & $102.1 \pm 1.1$ & $98.6 \pm 1.0$ & $36.3 \pm 1.0$ \\
\hline \multirow[t]{2}{*}{$\mathrm{Al}(\mathrm{III})$} & $98.8 \pm 2.1$ & $98.4 \pm 3.2$ & $98.4 \pm 1.9$ & $98.1 \pm 0.3$ & $92.8 \pm 0.7$ & $34.7 \pm 1.9$ \\
\hline & ${ }^{133} \mathrm{Cs}$ & ${ }^{137} \mathrm{Ba}$ & ${ }^{139} \mathrm{La}$ & ${ }^{140} \mathrm{Ce}$ & ${ }^{141} \operatorname{Pr}$ & $\overline{{ }^{146} \mathrm{Nd}}$ \\
\hline $\mathrm{Fe}(\mathrm{III})$ & $98.4 \pm 1.1$ & $88.2 \pm 0.3$ & $90.3 \pm 1.4$ & $94.3 \pm 1.0$ & $96.4 \pm 1.2$ & $90.4 \pm 1.1$ \\
\hline $\mathrm{Ca}(\mathrm{II})$ & $98.3 \pm 1.2$ & $98.3 \pm 0.5$ & $98.9 \pm 1.5$ & $92.5 \pm 0.8$ & $96.9 \pm 0.9$ & $99.2 \pm 1.2$ \\
\hline \multirow[t]{2}{*}{$\mathrm{Al}(\mathrm{III})$} & $92.7 \pm 1.2$ & $92.1 \pm 1.0$ & $94.3 \pm 1.1$ & $97.6 \pm 1.3$ & $101.8 \pm 2.0$ & $99.0 \pm 0.3$ \\
\hline & ${ }^{147} \mathrm{Sm}$ & ${ }^{157} \mathrm{Gd}$ & ${ }^{159} \mathrm{~Tb}$ & ${ }^{163} \mathrm{Dy}$ & ${ }^{165} \mathrm{Ho}$ & ${ }^{166} \mathrm{Er}$ \\
\hline $\mathrm{Fe}(\mathrm{III})$ & $100.8 \pm 0.9$ & $94.2 \pm 0.7$ & $92.9 \pm 0.7$ & $93.8 \pm 0.6$ & $88.6 \pm 1.1$ & $94.2 \pm 0.8$ \\
\hline $\mathrm{Ca}(\mathrm{II})$ & $102.7 \pm 2.9$ & $101.1 \pm 1.3$ & $101.9 \pm 2.0$ & $100.6 \pm 1.1$ & $96.8 \pm 1.8$ & $100.5 \pm 1.2$ \\
\hline \multirow[t]{2}{*}{$\mathrm{Al}(\mathrm{III})$} & $96.5 \pm 0.5$ & $91.7 \pm 0.6$ & $96.0 \pm 0.7$ & $96.9 \pm 1.0$ & $92.8 \pm 0.8$ & $98.9 \pm 0.9$ \\
\hline & ${ }^{169} \mathrm{Tm}$ & ${ }^{172} \mathrm{Yb}$ & ${ }^{175} \mathrm{Lu}$ & ${ }^{232} \mathrm{U}$ & ${ }^{239} \mathrm{Pu}$ & ${ }^{237} \mathrm{~Np}$ \\
\hline $\mathrm{Fe}(\mathrm{III})$ & $91.9 \pm 0.7$ & $96.7 \pm 0.7$ & $100.6 \pm 0.7$ & $96.4 \pm 3.2$ & $96.3 \pm 2.0$ & $96.0 \pm 0.7$ \\
\hline $\mathrm{Ca}(\mathrm{II})$ & $100.3 \pm 1.5$ & $100.8 \pm 1.0$ & $92.7 \pm 0.8$ & $96.1 \pm 3.3$ & $98.5 \pm 2.2$ & $95.4 \pm 0.6$ \\
\hline $\mathrm{Al}(\mathrm{III})$ & $99.5 \pm 0.7$ & $97.5 \pm 0.8$ & $98.0 \pm 0.5$ & $96.7 \pm 3.3$ & $98.5 \pm 2.1$ & $92.6 \pm 0.7$ \\
\hline
\end{tabular}

Table 4: Recoveries of eluted matrix elements for high $\mathrm{Al} / \mathrm{Ca} / \mathrm{Fe}$ initial $\mathrm{CyMe}_{4} \mathrm{BTPhen}$ (10 mM, $90 \mathrm{~min}$ ) separation of nuclear forensic matrix, analysis by alpha spectrometry, gamma spectroscopy and ICP-MS. (N.B. error calculated from instrument and method error plus one sigma, sample data averaged from $n=5$ analysis run in triplicate, all calibrated against a range of standards in the concentration ranges above). forensics investigation. Our method avoids use of multiple column techniques and generation of thiocyanate waste. All four triazine ligands tested were found to extract Am/Cm from the matrix after AGI-X8 chromatography with little complexation of competing ions.

$\mathrm{CyMe}_{4} \mathrm{BTPhen}$ was the best ligand for the procedure, as the improved Am/Cm extraction kinetics allow recoveries $>90 \%$ to be obtained in $90 \mathrm{~min}$. However, we believe all four ligands tested would be viable alternatives, and many are more easily accessed synthetically which may be of benefit to application in an analytical laboratory.

Overall, our investigation shows that these triazine ligands are capable of extracting Am/Cm from complex nuclear forensic matrices, including those with high level $\mathrm{Fe}$, $\mathrm{Ca}$ and $\mathrm{Al}$. We hope that this work can be utilised in nuclear forensic investigations and in the wider field of analytical radiochemistry to provide a new rapid method for Am/Cm separation.

Acknowledgement: Funding for this project was provided by AWE via a studentship to MAH. ICP-MS analyses were carried out by Mr Paul Lythgoe (School of Earth, Atmospheric and Environmental Sciences, The University of Manchester).

\section{References}

1. Mayer, K., Wallenius, M., Ray, I.: Nuclear forensics a methodology providing clues on the origin of illicitly trafficked nuclear materials. Analyst 130, 433 (2005).

2. Goldstein, S. L., Hensley, C. A., Armenta, C. E., Peters, R. J.: Environmental and human monitoring of americium-241 utilizing extraction chromatography and $\alpha$-spectrometry. Anal. Chem. 69, 809 (1997)

3. Wallenius, M., Mayer, K.: Age determination of plutonium material in nuclear forensics by thermal ionisation mass spectrometry. Fresenius, J. Anal. Chem. 366, 234 (2000).

4. Maxwell, S. L.: Rapid method for determination of plutonium, americium and curium in large soil samples. J. Radioanal. Nucl. Chem. 275, 395 (2008).

5. Maxwell, S. L., Culligan, B. K., Kelsey-Wall, A., Shaw, P. J.: Rapid radiochemical method for determination of actinides in emergency concrete and brick samples. Anal. Chim. Acta 701, 112 (2011).

6. Luisier, F., Alvarado, J. A. C., Steinmann, P., Krachler, M., Froidevaux, P. J.: A new method for the determination of plutonium and americium using high pressure microwave digestion and alpha-spectrometry or ICP-SMS. Radioanal. Nucl. Chem. 281, 425 (2009)

7. Lewis, F. W., Hudson, M. J., Harwood, L. M.: Development of highly selective ligands for separations of actinides from lanthanides in the nuclear fuel cycle. Synlett 2609 (2011).

8. Adam, C., Kaden, P., Beele, B. B., Müllich, U., Trumm, S., Geist, A., Panak, P. J., Denecke, M. A.: Evidence for covalence in a N-donor complex of americium(III). Dalton Trans. 42, 14068 (2013).

9. Lewis, F. W., Harwood, L. M., Hudson, M. J., Drew, M. G. B., Desreux, J. F., Vidick, G., Bouslimani, N., Modolo, G., Wilden, 
A., Sypula, M., Vu, T.-H., Simonin, J.-P.: Highly efficient separation of actinides from lanthanides by a phenanthroline-derived bis-triazine ligand. J. Am. Chem. Soc. 133, 13093 (2011).

10. Modolo, G., A. Wilden, A. Geist, D., Magnusson, R., Malmbeck, A.: Review of the demonstration of innovative solvent extraction processes for the recovery of trivalent minor actinides from PUREX raffinate. Radiochim. Acta 100 (8-9), 715 (2012).

11. Higginson, M. A., Marsden, O. J,. Thompson, P., Livens F, R., Heath, S, L., Separation of americium from complex radioactive mixtures using a BTPhen extraction chromatography resin. React. Funct. Polym. DOI: 10.1016/j.reactfunctpolym.2015.05.002 (2015).

12. Trumm, S., Geist, A., Panak, P. J., Fanghänel, T.: An improved hydrolytically-stable bis-triazinyl-pyridine (BTP) for selective actinide extraction. Solvent Extr. Ion Exch. 29, 213 (2011).

13. Hudson, M. J., Harwood, L. M., Laventine, D. M., Lewis, F. W.: Use of soft heterocyclic $\mathrm{N}$-donor ligands to separate actinides and lanthanides. Inorg. Chem. 52, 3414 (2013).
14. Whittaker, D. M., Griffiths, T. L., Helliwell, M., Swinburne, A. N., Natrajan, L. S., Lewis, F. W., Harwood, L. M., Parry, S. A., Sharrad, C. A.: Lanthanide speciation in potential SANEX and GANEX actinide/lanthanide separations using tetra- $\mathrm{N}$-donor extractants. Inorg. Chem. 52, 3429 (2013).

15. Laventine, D. M., Afsar, A., Hudson, M. J., Harwood, L. M.: Tuning the solubilities of bis-triazinylphenanthroline ligands (BTPhens) and their complexes. Heterocycles 86, 1419 (2012).

16. Turan, M. D., Safarzadeh, M. S.: Separation of zinc, cadmium and nickel from $\mathrm{ZnO}-\mathrm{CdO}-\mathrm{NiO}$ mixture through baking with ammonium chloride and leaching. Hydrometallurgy 119-120, 1 (2012).

17. Cockrell, G. M., Zhang, G., VanDerveer, D. G., Thummel, R. P., Hancock, R. D.: Enhanced metal ion selectivity of 2,9-di-(pyrid2-yl)-1,10-phenanthroline and its use as a fluorescent sensor for cadmium(II). J. Am. Chem. Soc. 130, 1420 (2008). 